\title{
Risk and Stigma: Students' perceptions and disclosure of 'disability' in Higher Education
}

\section{Abstract [187 words]}

There is a focus on increasing the numbers of students with disabilities to apply to and study in Higher Education (HE). Despite sector-wide criteria regarding what comprises a disability, there are still students who do not disclose a disability at the application stage. This study sought to explore perceptions of students across one UK university regarding their views and experiences of a range of disabilities and reasons why a disability may not be disclosed on application to HE. The findings suggest a lack of understanding regarding what constitutes a disability, and concerns that disclosure will negatively impact upon the application decision and disadvantage the student. This paper highlights the disconnect between the support that universities can provide to students with a disability and the perceptions that some students have about the disadvantages that disclosure can bring. The findings support initiatives at policy and practice level across the sector to recognise and address perceptions and experiences of risk and stigma that applicants may have but at the same time highlight that more needs to be done to reduce the anxieties and lack of clarity that some students experience.

\section{Key words [5-6]}

Higher Education students, disability, disclosure, risk, stigma, Fair Access

\section{Introduction}

This paper reports on a study of Higher Education (HE) students’ perceptions of what 'disability' means in the context of applying to a UK university. The study aimed to understand some of the complexities and experiences around perceptions and disclosure of disability at the initial formal point of contact with a university. For the purposes of this study, the categorisation and definitions of a disability were taken from UCAS (the UK's centralised Universities and Colleges Admissions Service) (Table 1)

Insert Table 1

A recent review of the applications and enrolment at a single UK university (XXX [deleted to preserve anonymity] 2015) identified that in the period 2010-2014 over 1,200 applicants (1.28\%) failed to disclose on their application forms whether they had a disability despite being given the opportunity to declare it. They conclude that those applicants were either unwilling to disclose or were not sure if they met the criteria of having a disability.

The aim of this study was therefore to explore why some students enter HE with a disability (as defined on the UCAS Form), but do not always declare it. In particular, we were keen to understand the extent to which some applicants were unsure whether or not they have a disability for the purposes of the question regarding disability on UCAS application forms 
and how the students themselves define 'disability'. Exploring students' perceptions and experiences of disability can enable more effective messages and support about what disability means at an individual level. This understanding and awareness can, in turn, inform policy and practice at institutional and sector level in enabling students to make more informed choices about disclosure of a disability at the point of application.

\section{Disabled students in HE: policy, practice and experiences}

The recent publication of the Inclusive Teaching and Learning in HE report by the Department for Education (2017) has reasserted the responsibility of HE providers to put into place strategies to support disabled students to succeed in HE. However this can only be initiated if the student discloses a disability to the university and their needs arising from this. Whilst there are numerous studies exploring disability and HE students at university (e.g. Beauchamp-Prior, 2012, Madriaga et al., 2011, Vickerman and Blundell, 2010; Ryan, 2005; 2007), research focusing directly on the application and admissions process is sparse. The literature around disability discussed here draws on the tensions between policy and practice, the disclosure of a disability and some of the actual or perceived consequences of such disclosure.

\section{Policy and practice of supporting disabled students in HE}

In the United Kingdom, there is national legislation (Equality Act 2010) to prevent the discrimination of disabled applicants to HE. This Act states that institutions must not discriminate against disabled applicants in the arrangements it makes for: deciding who is offered admission as a student; the terms on which it offers to admit the person as a student; not admitting the person as a student (Equality Act, 2010, para 91). More recently, the Department for Education (2017) established the role of HE institutions in embedding support for disabled students as part of their general pedagogic practices through inclusive curricula and teaching and learning resources.

It is recognised that there are international differences in supporting disabled students with some, such as Australia having similar policy approaches through, for example, the Disability Discrimination Act(1992) and the DDA Standards for Education of (2005). A comparative analysis of disabled student experiences at institutions in Sweden, the Czech Republic and the USA by Järkestig Berggren et al. (2016) concluded that “students' possibilities for equal participation are shaped by the institutional context that is based on medical diagnosis and compensation for an inaccessible education" (p.339). This, they noted, meant that students required a medical diagnosis in order to access any additional support, with the consequence of higher numbers of students leaving university with a registered disability than entering it.

This study focuses on the UK context, notwithstanding similarities and differences in policy and practice in other countries. Irrespective of this, the same question remains - how do universities (or indeed do universities) encourage students with a diagnosed or undiagnosed disability to apply for places? In the UK, government policy is supported through a range of initiatives. For example, in 2017 the Higher Education Funding Council for England (HEFCE) stated: 
"Our funding for disabled students is $£ 40$ million in 2017-18. The funding level increased from $£ 20$ million in 2015-16 to $£ 40$ million in 2016-17. This increase is to support institutions to meet the rapid rise in the number of students reporting mental health problems and to transition towards an inclusive social model of support for disabled students.” (HEFCE 2018a)

In the meantime, there have been 56\% more students with a known disability and 220\% more students with a known mental health condition entering UK universities since 2010-11 (HEFCE 2018b). The Office for Students (OfS, which replaced HEFCE in 2018) very firmly places the responsibility on universities to ensure that access to HE, inclusivity and learning and teaching environments meeting the needs of all disabled students are embedded in policy and practice at institutional level.

From the statutory perspective at least it seems that the UK admissions process is accessible for disabled students. However, as recently as 2015, Moola commented on the 'the lack of disability-friendly policies in higher education. Policy development is needed before curriculum changes can occur' $(2015,50)$. In the ground-breaking study of Scottish higher education undertaken by Tinklin and Hall (1999) five institutional obstacles were identified: 'the physical environment, accessing information, entrance to higher education, assumptions of 'normality' and levels of awareness' $(1999,187)$. They also argued that, whilst there may be assistance provided to overcome the obstacles, it does not remove them. This aligns with a study by Manago et al. (2017) into parents of disabled children who, they noted, demonstrated an awareness of the difference between the medical and the social model of understanding disability. The former 'emphasises diagnostic labels and treats impairment as an individual deficit, while the social model centralizes unaccommodating social structures' (Manago et al. 2017, 170). In their study, parents deployed strategic, affective and practical methods to deflect or challenge disability stigma, 'extracting from medical and social models of disability towards each end as they deemed fit' (Manago et al. 2017, 177) - never really changing the status quo but finding ways to best manage it for the well-being of their child.

The dilemma this presents to potential students, which aligns with issues of stigma and risk, is the conflict between perceiving and/or experiencing a disability as something that requires medical intervention in order to support or alleviate any disabilities versus a society (or perhaps in this case, a university) which fails or is perceived to fail to accommodate a range of needs that may be physical, psychological, cognitive, and intellectual. They conclude that there are now 'burgeoning claims among disability scholars and activists that neither model encompasses the entirety of the disability experience' (Manago et al. 2017, 176).

\section{Disclosure of a disability}

In much of the research, the issue of disclosure - a student identifying that they are disabled is seen one of the most important areas of the admissions process (Palombi, 2000), regardless of the education system. But, as Weedon and Riddell (2009: 145) noted, 'universities that see disclosure as a matter for the individual student, face difficulties reaching out to some students.' 
Disclosure of disability on application can lead to speedier access of support, and provide benefits to the students in terms of ensuring that any specific requirements are in place before they start university. However, there is still concern that disclosure can be a double-edged sword. Kravets (2006: 21) commented that 'thousands of students will not disclose because of lack of information or fear that the disclosure will negatively impact their chances of admission'. Although institutions are legally not allowed to deny any self-disclosing disabled student admission, providing they meet the academic requirements, there is clearly concern that this does not happen in practice. This is due, she argued, to those with hidden or undisclosed disabilities 'often lacking good information about services, programmes, accommodation and application procedures’ (Kravets, 2006: 22).

\section{Risk and Stigma}

Fear of disclosure is linked to issues of risk and stigma - that students will be negatively impacted on and/or that they will carry a 'label' which differentiates them from other students. Seminal work on stigma was led by Goffman (1963) who argued that it was '[an] attribute that is deeply discrediting and that reduces the bearer from a whole and usual person to a tainted and discounted one' (Goffman, 1963: 3). More recently, Link and Phelan (2001) defined stigma as 'when elements of labelling, stereotyping, separation, status loss and discrimination occur together in a power situation (p.337) which, as Gibbons and Birks (2016) suggested, is more applicable today. In her study of stigma and student mental health in HE, Martin (2010) found that students who did not disclose because of fear of discrimination and disadvantage were more likely to struggle with their studies, and feel isolated and fearful. So disclosing a disability may feel for some students as a risk not only to their chances of success at application stage, but also in terms of being labelled in a way that may negatively impact on their settling into and successfully progressing through university.

As outlined above, disability is heterogeneous, as is the way that disclosure is conceived, responded to and felt. Even then the decision to apply for help is connected with an anguished consideration of whether they should seek help and accept an identity as a 'disabled student' or not. Järkestig et al., (2016), Kravets (2006), Madriaga (2007), Weedon and Riddell (2009) all report that visible disabilities are easier to disclose than more hidden disabilities like Asperger syndrome, ADHD, mental health or learning disabilities.

This question of disclosure touches upon some core issues of disability in society - namely the erasure of disabled bodies. The research builds a consensus that part of the challenge of disclosure is the challenge of coming to terms with being, or more accurately, being seen as disabled (Madriaga, 2007, 409; see also Järkestig et al., 2016; Rowan, 2014; Saunders, 2010; Vidali, 2007; Weedon and Riddell, 2009). Not only does the voluntary disclosure during the UCAS process touch upon issues of identifying themselves as disabled, students are being asked to declare and define themselves in terms of relatively fixed categories. Roberts (2009) found that students assumed that that disclosing an impairment on their UCAS application form meant that they would be contacted by university and that their teaching staff would be informed. 
This study aims to contribute to the existing body of knowledge around perceptions and disclosure of disability at the initial formal point of contact with a university and how this can be used to reduce actual or perceived risk or stigmatisation. Through understanding this from the students' perspective, insights can be gained regarding the links between students' aspirations to gain a place at the university of their choice and the institution's commitment to and structure for encouraging and supporting applications from disabled students. Of particular interest is how students themselves define disability and what they perceive as the risks - or benefits - of disclosure of disability when applying to university.

\section{Methodology}

The methodological approach underpinning this study focused on understanding students' experiences and views. This interpretative approach embraced participatory research (Grant and Ramcharan, 2010) in that the fieldwork was conducted by students as co-researchers. This was integral to the study as we wished to illicit students' honest thoughts and perceptions regarding disability and the reasons for disclosure/non-disclosure and not those thoughts that could possibly be sanctioned by having academic staff as the researchers. Therefore, two students were recruited as Undergraduate Research Assistants (URAs) working closely with the experienced academics. The URAs were provided will full training and support in planning and undertaking qualitative research including ethical considerations, leading focus groups and analysing data. They were guided and supervised by two senior academics at all stages.

\section{Ethical Considerations}

Mindful of the potentially sensitive nature of the discussions, the URAs were trained in how to handle disclosure, distress or discomfort in a focus group setting. Ethical approval was granted by the University Research Ethics Committee. In particular both the confidentiality and anonymity of the discussions and data was assured to the student participants, as well as the voluntary nature of their participation and right to withdraw from the study. Where student excerpts have been used in this paper, the students have been provided with pseudonyms.

\section{Focus Groups}

Focus group methods were chosen because they provide an insight into the beliefs and attitudes that underline behaviour (e.g. Carey, 1994; Esmail et al., 2010) in a non-threatening open environment which was important given the negative labelling that can be associated with disability. In this study, we were interested in understanding how students, in a group situation, would exchange and articulate their perceptions and experiences of students deciding to enter HE with a diagnosed or suspected disability, but not always declaring it at the application stage. Discussing (or disclosing) disability can be a sensitive issue and consideration was given to the use of individual interviews instead. However, as the process of applying to university often requires applicants to discuss their application with peers, family members, school staff and others, we were interested in how these students articulate their ideas and perceptions in a group setting, and how the discussion develops. 
Purposeful sampling was used in that the URAs sent out a general email inviting expressions of interest from first year undergraduate students across the university to participate in a focus group to discuss factors that may affect student's decision to disclose or not a disability in their UCAS application. First year students were particularly targeted as they will have completed their UCAS application most recently. Included in the email was the participant information document explaining the purpose of the project and details of focus group meetings.

In total, 18 students participated in four focus groups - 5 males and 13 females of whom 15 were home students (from the United Kingdom) and 3 international students. Two were mature students aged over 21 years. Ten students stated that they had an existing disability or medical condition - six experienced a mental health condition (depression, anxiety and ADHD), two a physical condition (epilepsy and diabetes) and two a specific learning difficulty (dyslexia). They represented a range of UG programmes from across all four Faculties (health, media and communication, science and business). The participants were not asked to divulge other widening participation 'flags' such as first in family to university, ethnicity or class although it is acknowledged that in a larger study, this data would be helpful in further exploring whether or not these factors also contributed to students' perceptions and disclosure of disability.

The focus groups were run by the URAs and held on the university campus. Each lasted around 60 minutes and was audio recorded for later transcription and analysis. The focus groups posed two questions for the participants to explore: Thinking back to your UCAS application form and in particular the disability section, what were your thoughts on this? Why do you think some students chose not to answer this section? Following this general open discussion the participants were presented with the different categories of disability identified by UCAS (Table 1) and asked to explore their perceptions regarding whether they perceived each one to be a disability.

\section{Analysis}

The focus group data were analysed by the URAs and academic researchers using the process advocated by Braun and Clarke (2006). Initially, each focus group was transcribed verbatim by the two URAs. Each piece of transcribed data was then re-read line-by-line and initial codes were identified. These initial codes were then independently reviewed by the URAs to identify potential themes. In reviewing the themes, the URAs came together to share, discuss and redefine their initial themes. This was then shared with the academic researchers who worked with the URAs to further define and name the themes, identifying the overall themes extracted from the analysis.

\section{Findings}

From the analysis of the data three main themes and sub-themes were identified relating to personal, process and institutional issues (Table 2).

Insert Table 2 


\section{Personal}

This theme centred on the students' personal thoughts, experiences and understandings of the term 'disability' as well as their personal perceptions of the label 'disabled' on themselves and their lives.

\section{Personal: Perceptions and understandings around disability}

In all of the focus groups, there was discussion about what a disability actually is. For some individuals, they have normalised their disabilities and in doing so did not perceive themselves as disabled:

"Well I'm diabetic, so I put that down that I do have a disability. But it's weird because I've had it for 17 years so it's not like a disability to me; it's just part of my life” (Doug)

"Maybe because they've had it for a certain period of time it's kind of become part of normal life and they just don't really think twice about it sort of thing” (Jonny)

However for other participants there were uncertainties regarding the term 'disabled'. Will identifies that "the word disability is controversial in this day and age, because of the debate that's going on. Like - is it actually a disability or is it ableism?” It was felt that if a disability or long term medical condition has been diagnosed by a doctor it almost becomes an official label for an individual with a condition or impairment, one that they may reject or feel uncomfortable with. So by not declaring it on an application form, they are rejecting their own diagnosis and perceived label. This links to the notion of having 'voice' and, as Jason commented: "It is an act of defiance; a form of protest". In contrast Jonny highlights that "everyone will have a different point of view and different interpretation as to what the word disability means... so some people may consider it a negative thing and other people may consider it just a genuine medical term... they see no problem with’”.

Personal: Disclosing personal information and perceptions of disabled self

As Doug noted above, he does not consider his diabetes to be a disability and, because he is able to self-manage his condition, did not declare or seek help from the University. Others though felt that 'admitting' to having a disability, was admitting it to oneself:

"You are now this; you are not normal anymore" (Jonny)

"If you wouldn't even tell a friend, I don't think you would tell some random people" (Suzy)

"A lot of people are undiagnosed as well; like I've got slow processing, dyslexia, dyspraxia, and like - I just thought it was me, I thought it was normal” (Ginny)

"It's a big hurdle if you hadn't admitted to it before" (Petra)

For many, disclosing a disability at point of application was felt to be unnecessary and irrelevant and, because they were unclear about how disclosure would be handled in terms of confidentiality, they thought that many students would defer any declaration until they had started at university. This issue also highlighted the problem of whether or not to keep a 
disability or medical problem private or to make it public - partly an issues of "they might just refuse to tell themselves that they're disabled in any way or not want to accept it" (Jonny) or, as Will noted: “I've had depression but I didn't put it down because it doesn't affect me anymore, now. And it doesn't matter, it's personal, and I don't feel like it would affect my education or my learning. In that sense it's not relevant".

Personal: Perceived severity of disabilities, and distinction between mental and physical disabilities

There was a general acceptance that some disabilities are perceived as being more severe than others. Interestingly, mental health and specific learning differences were seen as different to a physical disability perhaps because these are often invisible and possible to 'cover up' during the application process. Ally's comments are typical of others in the groups:

"I think when people think about disabilities they think more about like wheelchairs and crutches and things like that; they don't like 'oh mental health issues' and things like that are issues as well”. (Ally)

Jason, however, recognised that mental health issues could 'technically' be categorised as a disability:

"I think it's quite non-specific so if somebody has something like maybe mental disability like anxiety or something like that, they wouldn't write it down because they don't think that they are properly disabled but they might technically be" (Jason)

Ally also differentiated between mental health conditions such as "schizophrenia which are fixed conditions versus something temporary, that can be treated - like depression”. Other conditions, such as diabetes were perceived as being a health issue, not a disability. As Petra commented: "I guess with mental disabilities unless you've been told by a doctor, you don't really label it yourself. Whereas physical you know of... know what you've got, you know what's wrong with you, because you can see it". Joe did not see any problems with distinctions between different types of disability: "Everyone will have a different point of view and different interpretation as to what the word 'disability' means... so some people may consider it a negative thing and other people may consider it just a genuine medical term...they see no problem with that”.

Process: Impact at university application level

Not knowing why UCAS or the universities want this information was a common theme across all focus groups, with some assuming it was to evidence a 'diversity quota' and others assuming it would be passed to the universities as part of the application process. In one focus group, all the respondents felt they would not look at university websites to help decide whether to declare a disability but would wait until they had actually started on their course and seek specific help then:

"UCAS is a bit too early and the wrong place to say what you have... and the long disabilities thing [the list on the UCAS form as per Table 1 above], because when you do UCAS you're applying to five different universities and it's not personal and it feels like 
you're on your own in front of these big universities whereas maybe if it's dealt with further down the line when you've got your uni then maybe you'd feel more at ease, when you know which university you're going to. UCAS is probably a bit too early for people to disclose their disabilities" (Ginny)

On the other hand, Nadia argued that "because it [the application] is so important, they wouldn't want to risk it - the risk associated with declaring a disability, the application could be rejected or turned down due to this factor”.

Process: Testing periods, unclear diagnosis or collateral diagnosis

Several respondents thought that some students applying may still be in the testing or assessment phase of diagnosis, so will put 'no' on the UCAS form as it is not definite, or will leave it blank as they are unsure and do not want to lie or for it to 'come back on them'. Jonny commented that "I couldn't explain my circumstances - I was in the process of being tested”.

On the other hand, some students may have been diagnosed in the past (for example, with depression) but feel it no longer affects their lives:

"You might get in trouble by trying to get something [i.e. support or additional funding] that you're not entitled to" (Lizzie).

“... because he's not in that place any more [suffering OCD]. I don't think he'd think it was relevant” (Petra),

Lizzie recounted the experience of one of her friends: "My flatmate's only just been diagnosed with anxiety, dyspraxia, dyscalculia and dyslexia, and only just now because she failed a unit... so obviously she didn't fill it out on her form because she didn't know" - a point supported by Ginny: "Sometimes we may feel that we have to be diagnosed by a doctor in order to say we have it... even though you can still have it without being diagnosed". So alongside other perceptions, is the uncertainty about whether a historical disability or medical condition 'counts', whether being in the process of being tested 'counts' or whether being able to self-manage effectively 'does not count'.

Process: Linguistics and wording of questions

The respondents felt that the word 'disability' carried negative connotations and noted that there is a difference between having an impairment and being classed as disabled. Will commented: "I don't know if I would use the word disability at all because it's labelling" whilst Jonny identified that "everyone will have a different point of view and different interpretation as to what the word disability means. So some people may consider it a negative thing and other people may consider it just a genuine medical term that they see no problem with". Doug summed up the discussion with "I think we've all agreed that it's like you're either in that box or you're not and there's no middle ground; it is just a disability box"

Process: The UCAS application process itself 
All the students acknowledged that they found completing the UCAS form time consuming and somewhat confusing, with a fear of 'getting it wrong' and therefore jeopardising their chances of successful offers from their universities of choice. In addition, many had to complete the form in a public space - usually at school, in front of teachers and peers, who they may not wish to know of any disability or medical condition. They recognised the importance of the Personal Statement in their application but also felt that, having completed details such as nationality, finance and past academic grades, by the time disability section was reached it seemed less important. There was also concern that the disability drop-down menu was populated by pre-determined criteria and conditions which did not allow for comment or explanation from the applicant.

They suggested that the form could be improved if the drop-down menu was available for viewing prior to declaring whether or not the applicant had a disability or medical condition, that there should be space to add in clarifying information next to each item on the list and that the disability section should be separate from the main application form.

\section{Institutional: Perceived stigma and discrimination}

"I think if you have a mental disability, the stigma attached to that could potentially be that people will think you're not of sound mind, that you could be unpredictable, people usually expect the worst...” (Jonny). The issue of real and perceived stigma attached to disabilities and medical conditions formed a significant part of the discussions. Several students sought the advice of parents and teachers in completing their applications, who may themselves have preconceived ideas about disability and any stigma attached, based on their own historical or cultural experiences. One student was told by her peers and mother not to put down her disability because of the way it might be received by the universities to which she was applying. Will noted the "fear of being treated differently". The perceived stigmatised views of disability discussed in the focus groups were, for example, that students with ADHD were viewed as disrupting the class, those with epilepsy were likely to have seizures in class, whilst diabetics are likely to need to inject in class.

Although the respondents recognised that many students with disabilities or long-term medical conditions were likely to be adept in self-management, there was still a fear that disclosure would jeopardise chances of university entry based on 'wider society' and its views of disability. Rohana "didn't want to get diagnosed because I wanted to have the same opportunities as other students without disabilities" whilst Lizzie argued that "there's a fear of being diagnosed and then it becoming official, and you having this label”.

Whilst one respondent noted that she had been discriminated against by an employer prior to coming to university, none of the respondents had any examples, anecdotes or rumours of other students who had been stigmatised or discriminated against on the basis of disability. But their perceptions of discrimination and stigma were deep-rooted and, to them, very real.

Institutional: Unknown impact of declaring information 
There was uncertainty as to whether universities receive this information from the UCAS form and, if so, whether students would be discriminated against, and not offered places. On the other hand, some respondents queried whether universities needed this information in order to demonstrate that they were meeting 'diversity criteria'. They felt a possible solution to this would be to declare a disability after the university had made the offer of a place.

The students felt they were unclear about the reasons for declaring this information, why it was important and who needed to know (i.e. just UCAS or just the university?). They were uncertain whether this information would be passed to the university so that there would be an actual offer of help and how confidential this information would remain in the future. Whilst students did "not want to get in trouble by trying to get something that you're not entitled to" (Rachel) they also did not want special treatment or 'fuss' that would separate them out from being mainstream students. Will suggested that it may be useful to have a "disclaimer at the end of the form so you know how it affects your application by filling it in, so how your university would contact you about it, so you know why you're doing it" notwithstanding that such information is already included in the section around disability!

\section{Institutional: International students}

The three international students, Ally, Rohana and Will, articulated some of their experiences and perceptions from their home country, noting that there are often significant differences between there and the UK.

Ally explained that "in Spain, uni is completely public and they don't have all the services or the money that they need to put in there so you wouldn't expect to find that [level of support]. It depends where you come from”. Rohana, from Romania, had to rely on a consultant to help with her application and did not know the perceptions of this consultant and what his advice or possible influence around supporting a disabled student may be. She said that "sometimes it's also about culture because in my country if you say you have a disability, you're just like pointed at, people point fingers at you, so you just prefer not to say or not be seen with a disability". Will, from the Netherlands, was confused by the whole UCAS form as "it doesn't work like that in my home country" and again he was unsure how any disclosures of disability would be used by UCAS or the universities. It was acknowledged that there are different cultural and procedural practices around disability across different countries but lack of clarity of what this meant to students applying for UK universities.

\section{Discussion}

We know from the literature that a key issue is whether or not students agree to describe themselves as disabled (e.g. Järkestig et al., 2016). Aligned with this is the 'resentment and fear of stigmatisation in disclosing their difficulties... [and]...feelings of guilt in asking for assistance’ Ryan (2005: 58). In the UK context, some students choose not to disclose because as Redpath et al. (2013: 1342) noted 'they felt this might disadvantage them during the application process'. Vickerman and Blundell (2010) found that students may not disclose a disability at application stage 'due to a perceived fear that they may not be offered a place on the course of their choice’ (2010: 26). 
This study has supported many of those findings. What is interesting is that these students have highlighted not only their 'incomplete knowledge' around what constitutes a disability for the purposes of declaration at university application stage, but also the assumptions and perceptions of how this declaration may be used. This uncertainty is combined with other worries about applying for university, particularly around getting into their preferred university, achieving the required grades and making the 'right' choices. It is clear from the respondents in this study that they do not want to start university by standing out at the beginning as 'different' - and this, in turn, links to successful transition, feelings of belonging and engagement (e.g. Thomas, 2012). Aligned with Manago et al. (2017)

Although the sample size for this study is small, and based at only one UK university, the purpose was to stimulate small group in-depth discussions that would enable an open and frank conversation of their experiences and perceptions. To develop these findings further, the study could be replicated at other single institutions (to help identify areas for local enhancement and improvement) and across institutions to explore perceptions and experiences of students across the sector, highlighting similarities and differences between different types of institutions and a wider range of students.

\section{Summary}

This study has found that some students do not categorise themselves as disabled or do not apply to the categories on the UCAS form to themselves - and are often nervous about the (assumed) consequences of disclosure. Three key themes were found in the research addressing issues of student perceptions of disability during the admissions process: personal, process and institutional. There still appears to be a disconnection or tension between these three. Students are making assumptions about the nature of disability and decisions to disclose based on their own (or other's) perceptions rather than actual evidence. The process of applying to University does not allow for 'grey' areas (such as short term, historical or asyet-undiagnosed disabilities) and institutions are not always providing clear reassurance to students about why they need this information and what they will do with it.

The challenge for HEIs and policy makers is to find ways for the personal, process and institutional experiences and expectations to be better integrated so that students are much clearer that declaring a disability can only help with an application as opposed to hinder. This is arguably of increasing importance due to the increase by $220 \%$ in the number of students reporting mental health issues which has emerged since this study was conducted (OfS, 2018).

Higher education is seen as an empowering and life-changing experience for students that can provide employment and personal opportunities often denied to disabled people. However, it is also recognised as being - or perceived to be - structured against the lives, bodies and experiences of disabled people. Despite legislation and policy, it is clear that prospective students are still unclear about what constitutes a disability, what risks or stigma may arise from disclosing one and what impact such disclosure may have on their application to study in the university of their choice. 
[Word count (not including references) - 5800]

\section{References}

Braun, V. and Clarke, V. (2006) 'Using Thematic Analysis in Psychology’. Qualitative Research in Psychology, 3: 77-101.

Carey, M. (1994) 'The Group Effect in Focus Groups: Planning, Implementing and Interpreting Focus Group Research’ in J. Morse (ed.) Critical Issues in Qualitative Research Method, London: Sage Publications.

Department for Education (2017) 'Inclusive Teaching and Learning in Higher Education as a route to Excellence’, [online]. Available at https://www.guildhe.ac.uk/wpcontent/uploads/2017/01/Inclusive_Teaching_and_Learning_in_Higher_Education_as _a_route_to_excellence.pdf [accessed: 3.11.17]

Esmail, S., Darry, K., Walter, A. and Knupp, H. (2010) 'Attitudes and perceptions towards disability and sexuality’, Disability and Rehabilitation, 32, 14: 1148-1155.

Gibbons, B and Birks, M (2016) 'Is it Time to Revisit Stigma? A Critical Review of Goffman 50 Years on', British Journal of Mental Health Nursing, 5, 4: 185-189.

Goffman, E. (1963) Stigma: Notes on the Management of Spoiled Identity, Englewood Cliffs, NJ: Prentice-Hall.

Grant, G. and Ramcharan, P. (2010) 'User Involvement in Research’ in K. Gerrish and A. Lacey, The Research Process in Nursing, Chichester: Wiley-Blackwell.

XXX [Reference deleted to preserve anonymity] Admissions and Enrolment: Analysis of XX Data Set 2010-2014. XX University.

HEFCE (2018a) Policy Guide: Supporting Disabled Students at http://www.hefce.ac.uk/sas/disabled// (accessed 31 May 2018)

HEFCE (2018b) Student Characteristics (Disability) at: https://www.officeforstudents.org.uk/data-and-analysis/polar-participation-of-local-areas/ (accessed 1June 2018)

HESA (2017) Changes and Trends in the Student Population, Higher Education Statistics Agency, at: https://www.hesa.ac.uk/news/09-02-2017/changes-and-trends-studentpopulation (accessed: 20 February 2018)

Järkestig Berggren, U., Rowan, D., Bergbäck, E., and Blomberg, B. (2016) Disabled Students' Experiences of Higher Education in Sweden, the Czech Republic, and the 
United States - A Comparative Institutional Analysis’, Disability and Society, 31, 3: 339-356.

Kravets, M. (2006) 'Hidden Disabilities: Another Diverse Population', Journal Of College Admission, 190: 18-25.

Madriaga, M. (2007) 'Enduring Disablism: Students with Dyslexia and Their Pathways into UK Higher Education and beyond’, Disability and Society, 22, 4: 399-412.

Madriaga, M., Hanson, K., Kay, H., and Walker, A. (2011) 'Marking-Out Normalcy and Disability in Higher Education', British Journal of Sociology Of Education, 32, 6: 901-920.

Manago, B., Davis, J. L. and Goar, C. (2017) 'Discourse in Action: Parents’ use of medical and social models to resist disability stigma’, Social Science \& Medicine, 184: 169177

Martin, J. M (2010) 'Stigma and Student Mental Health in Higher Education', Higher Education Research and Development, 29:3, 259-274, DOI: 10.1080/07294360903470969.

Moola, F. (2015) 'The Road to the Ivory Tower: The Learning Experiences of Students with Disabilities at the University of Manitoba', Qualitative Research In Education, 4, 1: 45-70. doi:10.4471/qre.2015.56

Palombi, B. J. (2000) 'Recruitment and Admission of Students with Disabilities', New Directions for Student Services, 91, 31-39.

Redpath, J., Kearney, P., Nicholl, P., Mulvenna, M., Wallace, J., and Martin, S. (2013) 'A Qualitative Study of the Lived Experiences of Disabled Post-Transition Students in Higher Education Institutions in Northern Ireland', Studies in Higher Education, 38, 9: 1334-1350.

Riddell, S., Tinklin, T., and Wilson, A. (2005) 'New Labour, Social Justice and Disabled Students in Higher Education. British Educational Research Journal, 31, 5: 623-643.

Roberts, H. (2009) 'Listening to Disabled Students on Teaching, Learning and Reasonable Adjustments' in Fuller, M., Georgeson, J., Healey, M., Hurst, A., Kelly, K., Riddell, S., Roberts, H., and Weedon, E. (eds) Improving Disabled Students’ Learning: Experiences and Outcomes, London: Taylor and Francis.

Rowan, L. (2014) 'University Transition Experiences of Four Students with Dyslexia in New Zealand', Australian Journal of Learning Difficulties, 19, 2:129-136.

Ryan, J. (2005) 'Uni is a serious thing, why are you here if you've got learning difficulties?': Access and Exclusion in Higher Education. Melbourne Studies in Education, 46, 1: 45. doi:10.1080/17508480509556415. 
Thomas, L. (2012) Building Student Engagement and Belonging in Higher Education at a Time of Change. Paul Hamlyn Foundation, 100.

Tinklin, T. and Hall, J. (1999) 'Getting Round Obstacles: Disabled Students' Experiences in Higher Education in Scotland', Studies in Higher Education, 24, 2: 183-194.

UCAS (2018) 'Students with Disabilities’, University Central Admissions System, at https://www.ucas.com/ucas/undergraduate/getting-started/individual-needs/studentsdisabilities. (accessed 13 January 2018).

Vickerman, P. and Blundell, M. (2010) 'Hearing the Voices of Disabled Students in Higher Education’, Disability and Society, 25, 1: 21-32.

Weedon, E. and Riddell, S. (2009) 'Troublesome Transitions?: Disabled Students' Entry into and Journey Through Higher Education’ in Fuller, M., Georgeson, J., Healey, M., Hurst, A., Kelly, K., Riddell, S., Roberts, H., and Weedon, E. (eds $\backslash$ ) Improving Disabled Students' Learning: Experiences and Outcomes, London: Taylor and Francis. 


\section{Tables}

Table 1: Admissions Guidance on Disabilities, UCAS, 2018

\begin{tabular}{|l|l|}
\hline a social/communication impairment & $\begin{array}{l}\text { e.g. Asperger, ADHD/ADD, and individuals on } \\
\text { the Autistic Spectrum }\end{array}$ \\
\hline a visual impairment & \\
\hline a serious hearing impairment & e.g. cancer, diabetes, epilepsy, ME \\
\hline a long standing medical condition & e.g. anxiety, Bipolar \\
\hline an ongoing mental health condition & e.g. dyslexia, dyspraxia and dyscalculia \\
\hline a specific learning difficulty & \\
\hline $\begin{array}{l}\text { a physical impairment or mobility } \\
\text { issue }\end{array}$ & \\
\hline
\end{tabular}

Table 2: Main themes and sub-themes emerging from the data

\begin{tabular}{|l|l|}
\hline Main Theme & Sub Theme \\
\hline Personal & $\begin{array}{l}\text { 1. Perceptions and understanding around disability } \\
\text { 2. Disclosing personal information and perceptions of disabled self }\end{array}$ \\
& $\begin{array}{l}\text { 3. Perceived severity of disabilities, and distinction between mental } \\
\text { and physical disabilities }\end{array}$ \\
\hline Process & $\begin{array}{l}\text { 1. Impact at university application level } \\
\text { 2. Testing periods, unclear diagnosis or collateral diagnosis }\end{array}$ \\
& $\begin{array}{l}\text { 3. Linguistics and wording of questions } \\
\text { Institutional }\end{array}$ \\
& $\begin{array}{l}\text { 1. Perceived stigma and discrimination } \\
\end{array}$ \\
& 2. Unknown impact of declaring information \\
\end{tabular}

